\title{
Factors Related to Adolescent Computer Use and Electronic Game Use
}

\author{
Jennifer A. Epstein \\ Division of Prevention and Health Behavior, Department of Public Health, Weill Cornell Medical College, \\ 402 East 67th Street, Suite LA-012, New York, NY 10065, USA \\ Correspondence should be addressed to Jennifer A. Epstein, jepstein@med.cornell.edu
}

Received 16 August 2011; Accepted 15 September 2011

Academic Editor: D. M. Ivanovic

Copyright ( 2012 Jennifer A. Epstein. This is an open access article distributed under the Creative Commons Attribution License, which permits unrestricted use, distribution, and reproduction in any medium, provided the original work is properly cited.

The goal of the research was to determine the association between a variety of factors and amount of time per week on the computer and electronic games. Participants (aged 13-17 years and residing in the United States) were recruited via the Internet to complete an anonymous survey on line using a survey tool. The target sample of 200 participants who completed the survey was achieved. The sample's average age was 16 predominantly female (63\% girls). A series of regressions with computer use and electronic games hours per week as dependent variables were run. Based on the results, boys engaged in many of the computer and electronic game activities more hours per week than girls. Neck and shoulder pain were implicated in greater use of computers and the Internet. Reading level was positively associated with computer use while math level had a negative association with computer use. These findings seem to suggest that greater computer and electronic use are associated with a number of negative factors and some positive.

\section{Introduction}

Very little research focuses on factors related to adolescent computer use and electronic game use. Some consider excessive video game or Internet game use to be a form of addiction $[1,2]$. The relationship between initiation or current past month substance use with greater computer/electronic game use may be a case of associating problem behaviors based on a problem behavior theory approach [3]. Video game use was linked to greater drug use, drinking behaviors (alcohol use) among young adults [4]. Internet use itself may involve exposure to tobacco and alcohol products through advertising on line and product placement in uploaded videos on popular sites. An earlier study found that past month drinkers used the computer more frequently per week excluding school but not for school work [5]. The overall issue of addiction related to computer use remains controversial, thus examining other factors related to adolescent computer and electronic game use would be most enlightening. Using the Internet for school fostered positive aspects [4]. Use of computer games was associated with lower academic performance [6], and excessive electronic game use among Thai adolescents was associated with lower grades [7]. More research needs to determine if the school use versus nonschool/recreational matters in the relationship between electronic use and educational measures.

Other research found that frequent computer-related activities were an independent risk factor for neck-shoulder pain and lower back pain among Finnish adolescents [8]. Greater time spent watching television and computer gaming was related to lack of sleep in children [9]. Computer time had a strong impact on bedtime and contributing to less sleep among American teens [10]. Computer use is a sedentary activity and has become common among adolescents. As a consequence, it might be expected that greater time on the computer and particularly the Internet might be associated with greater body mass index (BMI). Increased screen time among high school teens supported the displacement hypothesis [11] whereby in this case increased screen time reduces discretionary time for physical activity in one study [12]. Electronic games might involve more movement or physical activity, in certain cases depending on the game console (e.g., Wii) and type of game played (e.g., sports). 
Hypotheses. Substance use may be associated with greater computer use in particular nonschool use and electronic game use as suggested by earlier research and claims of those who believe that computer/game use can be addictive. Computer use, in particular when related to school, may be related to better academic outcomes (grades, reading level, math level) as suggested by some prior work. Computer use and electronic game use may be related to pain measures (e.g., neck/shoulder pain and lower back pain). Greater computer time could be related to less sleep. Based on the displacement hypothesis, screen activity may preclude less sedentary pursuits and be associated with higher BMI. This study will test these various hypotheses together, not separately as in prior research.

\section{Method}

Adolescents residing in the United States responded to recruitment efforts for an anonymous survey via the Internet (e.g., web sites with lists of psychology studies, of blogs listing studies) and word of mouth from the Internet recruitment (teachers, friends) during the 2009-2010 academic year. This study and recruitment effort, which was approved by the Institutional Review Board (IRB), was conducted online about computer use and health on a popular on line survey tool. The IRB required that data must be anonymous due to the adolescent age group. These recruitment efforts resemble those used prior to the Internet: flyers requesting volunteers for a study, listings of studies on bulletin boards for students, and announcements or listings of studies for psychology students. After reading a description of the study and their rights as anonymous participants, adolescents indicated whether they did not want to proceed with the study or proceeded to the next page indicating their willingness to participate in the study (informed consent). At study design, it was decided to recruit participants until there was useable data for at least 200 participants. The target sample of at least 200 participants was achieved. The target population was adolescents aged from 13 to 17, attending school, who use the computer/Internet during the academic year 2009-2010. In addition, the target population would consist of adolescents willing to complete the survey regarding health and computer use, as participation was voluntary. They answered items about computer use/electronic game use, demographics, health behaviors, and educational achievements. At the end of the survey, they were free to indicate any comments. Conducting online surveys using the Internet has become useful as a tool [13]. Recruitment through the Internet was thought to be an ideal way to locate adolescents with involvement with computers and the Internet for the current exploratory study. Any duplicated data or incomplete surveys were not included in the analyses.

Procedure. Participants were directed to a link to a survey through the recruitment or found the link via an Internet search on their own or from others (websites, teachers, and friends). Once they clicked on the link, they were presented with a one-page description of the online anonymous survey and their rights as research participants. Adolescents who proceeded to the next page indicating their agreement to participate (informed consent) indicated their responses to a number of items including the following used in the current study: age, gender, (calculated) body mass index (BMI), age when first used computer (range from 5 to 13 years old), and academic performance. Next, they indicated the usual number of hours per week they spent on (a) the computer for school work, (b) the computer excluding school work, (c) games for computer, (d) games for Internet, (e) games for handheld devices, and (f) games for game consoles. In addition, participants marked "yes" or "no" to a series of questions about pain related to computer use or electronic game use: neck, shoulder pain, lower back pain, wrist pain, and other pain. The respondents checked "yes" or "no" to a series of statements regarding their substance use: "I have smoked cigarettes or used tobacco," "I have smoked cigarettes or used tobacco in the past month," "I drank alcohol (excluding for religious purposes)," "I drank alcohol in the past month (excluding for religious purposes)," "I have used other drugs not prescribed to me" and "I have used other drug not prescribed to me." Other items were included to determine the average hours of sleep per night, reading grade level, and math grade level.

\section{Results}

Sample. The sample was predominantly girls $(63 \%)$, who had a mean age of $16.07(\mathrm{SD}=1.26)$ years old, and their mean age at first computer use was $7.30(\mathrm{SD}=2.29)$ years old. The target group was adolescents between the ages of 13 and 17, which included middle/junior high school, high school, and college students. Moreover, they read that they should live in the United States to participate. All work was conducted in accordance with the Declaration of Helsinki. The responsible Ethical Committee (as noted previously the IRB) approved the study and its measures. The sample appeared to be of adolescent students using computers which was the target audience and reason for the online survey. The majority specified school, teacher, class, or psychology website as means of finding out about the study. An earlier study used this sample and some of the measures from the larger project [5]. The focus in that study was on the relationship between alcohol use specifically and computer use, with the addition of Internet activities as outcome measures using ANOVAs. Since past month, alcohol use was related to computer use excluding school work based on the ANOVAs, it was felt that it should be included in the current study. The present study also tested public health and educational measures in a series of fuller regression models, not ANOVAs. Moreover, except for two of the measures of computer use, the earlier study also focused on Internet activities [5] and the present study instead focused on electronic game use. Thus there is a small level of overlap but the present study tests more hypotheses with other variables and examines electronic game use.

A series of multiple regressions with the six computer and electronic game hours per week measures as dependent measures (the computer excluding school work, the computer for school work, games for computer, games for Internet, games 
TABLE 1: Regression model for number of hours on the computer excluding school work per week.

\begin{tabular}{|c|c|c|c|c|c|}
\hline \multicolumn{6}{|c|}{ Coefficients } \\
\hline \multirow{2}{*}{ Model } & \multicolumn{2}{|c|}{ Unstandardized coefficients } & \multirow{2}{*}{$\begin{array}{c}\text { Standardized coefficients } \\
\text { Beta }\end{array}$} & \multirow{2}{*}{$t$} & \multirow{2}{*}{ Sig. } \\
\hline & $B$ & Std. error & & & \\
\hline (Constant) & 33.131 & 5.639 & & 5.875 & .000 \\
\hline Gender $(0=$ girls $1=$ boys $)$ & 4.773 & 1.867 & .178 & 2.557 & .011 \\
\hline Age first computer use & -1.351 & .380 & -.241 & -3.559 & .000 \\
\hline Neck and shoulder pain (Yes/No) & -5.264 & 1.942 & -.187 & -2.710 & .007 \\
\hline $\begin{array}{l}\text { Drank alcohol in the past month } \\
\text { excluding for religious purposes (Yes/No) }\end{array}$ & -4.019 & 1.857 & -.144 & -2.164 & .032 \\
\hline My reading level is grade \#- & 1.623 & .458 & .398 & 3.546 & .000 \\
\hline My math level is grade \#- & -1.052 & .471 & -.249 & -2.236 & .026 \\
\hline
\end{tabular}

TABLE 2: Regression model for number of hours on the computer for school work per week.

\begin{tabular}{|c|c|c|c|c|c|}
\hline \multicolumn{6}{|c|}{ Coefficients } \\
\hline \multirow{2}{*}{ Model } & \multicolumn{2}{|c|}{ Unstandardized coefficients } & \multirow{2}{*}{$\begin{array}{c}\text { Standardized coefficients } \\
\text { Beta } \\
\end{array}$} & \multirow{2}{*}{$t$} & \multirow{2}{*}{ Sig. } \\
\hline & $B$ & Std. error & & & \\
\hline (Constant) & 7.997 & 2.272 & & 3.520 & .001 \\
\hline Neck and shoulder pain (Yes/No) & -2.553 & 1.139 & -.151 & -2.241 & .026 \\
\hline My reading level is grade \#- & 1.032 & .275 & .425 & 3.745 & .000 \\
\hline My math level is grade \#- & -.619 & .285 & -.245 & -2.174 & .031 \\
\hline
\end{tabular}

for handheld devices, and games for game consoles) were performed using SPSS Version 18. The variables entered into the full regression models for each of these variables were age, gender, BMI, age when first used computer, academic performance (grades), measures of pain related to computer or electronic game use, measures about substance use, average hours of sleep, reading grade level, and math grade level. After each of these full models was run, variables that were not significant were deleted from the relevant model. The trimmed models were then tested and only included the significant effects [14].

The trimmed regression model for number of hours on the computer excluding school work was highly significant $F(6,194)=5.83, P>.0001$. Table 1 shows the results. Boys engaged in significantly more hours of computer use excluding school work than girls. Age of first computer use was negatively related to greater recreational computer use. Therefore, the younger an individual was when starting computer use was associated with greater weekly recreational use. Neck and shoulder pain were significantly associated with greater weekly computer use excluding school work. Drinking in the past month was also significantly related to this measure. Higher reading grade level was positively associated at significant levels with greater computer use excluding school work. However, lower math grade level was related at significant levels with higher computer use excluding school work. The overall trimmed model for computer use per week for school work was highly significant, $F(3,204)=6.37$, $P<.0001$. Table 2 shows the results. Neck and shoulder pain were also significantly associated with hours spent on the computer per week for school work. As with computer use not for school, high reading grade level was related to greater computer use per week for school work, while low math grade level was related to high computer use.

The trimmed multiple regression model for games for the computer per week was highly significant, $F(2,195)=7.21$, $P<.001$. See Table 3 for the results. Boys played computer games significantly longer compared to girls. Students with lower grades played computer games significantly more than students with higher grades. The overall trimmed regression model for games for Internet hours per week was highly significant, $F(4,167)=5.73, P<.0001$. Table 4 shows the results. Boys spent significantly more time playing games for the Internet than girls did. The higher body mass index of the participant indicated significantly greater time playing games for the Internet than individuals with lower body mass index. Individuals who experienced neck and shoulder pain played significantly more time on games for the Internet than those who did not experience such pain. Finally, adolescents who drank alcohol in the past month tended to play greater amount of time per week on the Internet than adolescents who did not drink in the past month.

The overall trimmed model for games for handheld devices hours per week was significant but only included two individual terms, $F(2,174)=6.25, P<.01$. Other pain was associated with greater time played on handheld devices (beta $=-.15, P<.05$ ) and low grades were also related to higher time played on handheld devices as measured by hours per week (beta $=.21, P<.01$ ). The trimmed regression model for games for game consoles hours per week was highly significant, $F(4,184)=13.63, P<.0001$. Table 5 shows the results. Boys played longer on games for 
TABLE 3: Regression model for games for computer hours per week.

\begin{tabular}{|c|c|c|c|c|c|}
\hline \multicolumn{6}{|c|}{ Coefficients } \\
\hline \multirow{2}{*}{ Model } & \multicolumn{2}{|c|}{ Unstandardized coefficients } & \multirow{2}{*}{$\begin{array}{c}\text { Standardized coefficients } \\
\text { Beta }\end{array}$} & \multirow{2}{*}{$t$} & \multirow{2}{*}{ Sig. } \\
\hline & $B$ & Std. error & & & \\
\hline (Constant) & 1.965 & .820 & & 2.396 & .018 \\
\hline Gender $(0=$ girls $1=$ boys $)$ & 1.830 & .662 & .193 & 2.765 & .006 \\
\hline At school my grades are mostly (high to low) & .876 & .409 & .150 & 2.142 & .033 \\
\hline
\end{tabular}

TABLE 4: Regression model for games on the internet hours per week.

\begin{tabular}{|c|c|c|c|c|c|}
\hline \multicolumn{6}{|c|}{ Coefficients } \\
\hline \multirow{2}{*}{ Model } & \multicolumn{2}{|c|}{ Unstandardized coefficients } & \multirow{2}{*}{$\begin{array}{l}\text { Standardized coefficients } \\
\text { Beta }\end{array}$} & \multirow{2}{*}{$t$} & \multirow{2}{*}{ Sig. } \\
\hline & $B$ & Std. error & & & \\
\hline (Constant) & 5.597 & 1.829 & & 3.061 & .003 \\
\hline Gender $(0=$ girls $1=$ boys $)$ & 1.759 & .608 & .217 & 2.892 & .004 \\
\hline Body mass index & .155 & .055 & .209 & 2.842 & .005 \\
\hline Neck and shoulder pain (Yes/No) & -1.974 & .650 & -.231 & -3.039 & .003 \\
\hline $\begin{array}{l}\text { I drank alcohol in the past month } \\
\text { excluding for religious purposes (Yes/No) }\end{array}$ & -1.022 & .615 & -.121 & -1.661 & .099 \\
\hline
\end{tabular}

game consoles as measured by hours per week than girls did. The younger individuals when they first started using the computer, spent more time on game consoles than individuals who started using the computer at an older age. Participants who smoked in the past month engaged in longer play on game consoles than those who did not smoke in the past month. Individuals with lower grades spent more time on game consoles than those with higher grades.

\section{Discussion}

Boys spent consistently more time per week on the computer excluding school work, on games for computer, and on games for Internet and on game consoles with no gender differences on computer use related to school work and using handheld devices. As handheld devices have games targeted to girls or gender neutral and include cell phones, it makes sense that no gender difference was found for this device or in computer use related to school work. Earlier research found sex differences for adolescents in computer use, Internet use, Internet attitudes, and computer technology, supporting the notion that girls engage less frequently than boys in technology, have less positive attitudes and more computer anxiety [15]. Yet, that study found no differences in mobile phone use. The younger an individual was when he/she started using computers, the greater his/her computer use was excluding school work and the higher his/her time playing with game consoles.

Low grades were associated with greater time spent weekly on: game use (computer games, handheld devices, and game consoles but excluding computer use in general and Internet games). Lower math grade levels were also related to greater time spent weekly on computer use (both excluding and including school work) but not game use. In contrast, high reading grade levels were associated with greater time spent weekly on computer use (both excluding and including school work) but not game use. Pain measures were related to certain computer and electronic game use measures. As in past research [8], neck and shoulder pain were associated with greater computer use (both excluding and including school work, games for the Internet). Interestingly, other pain was related to greater use of handheld devices. This is to be expected as these devices affect different areas of the body. Past month drinking was associated with higher weekly hours spent on the computer excluding school work. Drinking in the past month also tended to be related to greater number of hours per week spent on the computer using games for the Internet similar to past work with college students in which drinking was associated with video game use [4]. In addition, past month smoking was associated with greater number of hours per week on game consoles. These results are suggestive that substance use and recreational computer and game console use may both share aspects of being problem behaviors [3]. Higher BMI was associated with greater numbers of hours per week on games for the Internet. These games encourage the participants to remain sedentary for longer periods of time relative to the other activities. This finding resembled earlier research where increased screen time reduced discretionary time for physical activity [12].

The current study had several strengths and limitations. This study added more information to a small literature about factors associated with greater computer and electronic game use and made a distinction between computer use for school work and excluding school work. Among its other strengths was including a variety of computer and 
TABLE 5: Regression model for game consoles hours per week.

\begin{tabular}{|c|c|c|c|c|c|}
\hline \multicolumn{6}{|c|}{ Coefficients } \\
\hline \multirow{2}{*}{ Model } & \multicolumn{2}{|c|}{ Unstandardized coefficients } & \multirow{2}{*}{$\begin{array}{c}\text { Standardized coefficients } \\
\text { Beta }\end{array}$} & \multirow{2}{*}{$t$} & \multirow{2}{*}{ Sig. } \\
\hline & $B$ & Std. error & & & \\
\hline (Constant) & 9.046 & 2.049 & & 4.415 & .000 \\
\hline Gender $(0=$ girls $1=$ boys $)$ & 2.680 & .602 & .292 & 4.450 & .000 \\
\hline Actual age first computer use & -.289 & .133 & -.144 & -2.170 & .031 \\
\hline $\begin{array}{l}\text { I have smoked cigarettes or used tobacco in } \\
\text { the past month (Yes/No) }\end{array}$ & -2.574 & .807 & -.217 & -3.190 & .002 \\
\hline At school my grades are mostly (high to low) & 1.149 & .388 & .205 & 2.963 & .003 \\
\hline
\end{tabular}

electronic game use measures to determine which activities in specific had relationships with a variety of demographic, academic, or public health variables. A limitation is that these results only apply to adolescents who responded to an online study either due to academic reasons or pure interest. Moreover, these results do not address clinical issues as the study did not focus on people with a problem with excessive use of computers or electronic games. The study is limited due to its cross-sectional nature; it is not possible to draw conclusions about causality. Computer and electronic game use measures were limited to number of hours played per week. As one of the participants suggested in the comment section, measures of number of hours per month would be an improvement. Future research should examine the relationships covered in this study longitudinally.

There are several implications of the present study. Since neck and shoulder pain were associated with greater time spent on a couple of computer activities, it would be advisable to take frequent breaks, ensure that posture is proper and that activities are not engaged in for prolonged periods. Similarly, in the case of other pain being related to increased time spent on handheld devices, adolescents should take frequent breaks, rest from repetitive activities, and avoid engaging in activities for prolonged periods. The relationships between substance use and several computer and electronic game activities imply potential links between the two are problem behaviors. Yet future longitudinal research must delve into this relationship more fully. Although BMI only showed up for one computer activity (games on the Internet), it is possible that playing games on the Internet is particularly sedentary and encourages people to become overly engaged. In contrast, people with high BMI might be particularly attracted to games on the Internet as a way to socialize. Future research needs to examine this relationship longitudinally and determine why it exists.

The positive relationship between higher reading grade levels and computer use both for school work and excluding school work implies that adolescents most likely engage in activities that help their reading ability through their use of the computer (e.g., doing research for school, writing for school or other purposes). Conversely, lower math levels were associated with increased computer use for school work and excluding school work. It is less clear as to why this was the case except that on other measures (games for computer, handheld devices, and game consoles) lower grades were related to greater time spent on these activities per week. To the extent that math was not used during computer use for school work and excluding school work that would explain its failure to have a positive relationship. Yet its negative relationship is not addressed except as it is not apparently being helped through computer use. Future research needs to determine why this is the case. As for lower grades, it appears that adolescents engaging in more hours per week on games for the computer, handheld devices, and game consoles may be spending less time studying. These findings are also congruent with a similar association found between electronic game use and games among Thai adolescents [7]. In summary, further longitudinal research is needed to understand the relationships found and explored in the present study.

\section{Acknowledgment}

This research was supported by a Grant from the National Science Foundation (NSF0960391) to Dr. J. A. Epstein. No competing financial interests exist.

\section{References}

[1] J. S. Lemmens, P. M. Valkenburg, and J. Peter, "Development and validation of a game addiction scale for adolescents," $\mathrm{Me}$ dia Psychology, vol. 12, no. 1, pp. 77-95, 2009.

[2] B. D. Ng and P. Wiemer-Hastings, "Addiction to the Internet and online gaming," Cyberpsychology and Behavior, vol. 8, no. 2, pp. 110-113, 2005.

[3] R. Jessor, "Risk behavior in adolescence: a psychosocial framework for understanding and action," Journal of Adolescent Health, vol. 12, no. 8, pp. 597-605, 1991.

[4] L. M. Padilla-Walker, L. J. Nelson, J. S. Carroll, and A. C. Jensen, "More than a just a game: video game and internet use during emerging adulthood," Journal of Youth and Adolescence, vol. 39, no. 2, pp. 103-113, 2010.

[5] J. A. Epstein, "Adolescent computer use and alcohol use: what are the role of quantity and content of computer use?" Addictive Behaviors, vol. 36, no. 5, pp. 520-522, 2011.

[6] T. Willoughby, "A short-term longitudinal study of internet and computer game use by adolescent boys and girls: prevalence, frequency of use, and psychosocial predictors," Developmental Psychology, vol. 44, no. 1, pp. 195-204, 2008. 
[7] S. Jaruratanasirikul, K. Wongwaitaweewong, and P. Sangsupawanich, "Electronic game play and school performance of adolescents in southern Thailand," Cyberpsychology and Behavior, vol. 12, no. 5, pp. 509-512, 2009.

[8] P. T. Hakala, A. H. Rimpelä, L. A. Saarni, and J. J. Salminen, "Frequent computer-related activities increase the risk of neckshoulder and low back pain in adolescents," European Journal of Public Health, vol. 16, no. 5, pp. 536-541, 2006.

[9] E. Heins, C. Seitz, J. Schüz et al., "Bedtime, television and computer habits of primary school children in Germany," Gesundheitswesen, vol. 69, no. 3, pp. 151-157, 2007.

[10] K. L. Knutson and D. S. Lauderdale, "Sociodemographic and behavioral predictors of bed time and wake time among US adolescents aged 15 to 17 years," Journal of Pediatrics, vol. 154, no. 3, pp. 426-e1, 2009.

[11] D. C. Mutz, D. F. Roberts, and D. P. van Vuuren, "Reconsidering the displacement hypothesis: television's influence on children's time use," Communication Research, vol. 20, pp. 5175, 1993.

[12] T. A. Barnett, J. O'Loughlin, C. M. Sabiston et al., “Teens and screens: the influence of screen time on adiposity in adolescents," American Journal of Epidemiology, vol. 172, no. 3, pp. 255-262, 2010.

[13] M. Van Selm and N. W. Jankowski, "Conducting online surveys," Quality and Quantity, vol. 40, no. 3, pp. 435-456, 2006.

[14] J. Cohen, P. Cohen, S. G. West, and L. S. Aiken, Applied Multiple Regression/Correlation Analysis for the Behavioral Analysis, Lawrence Erlbaum, Mahwah, NJ, USA, 3rd edition, 2003.

[15] H. Rees and J. M. Noyes, "Mobile telephones, computers, and the Internet: sex differences in adolescents' use and attitudes," Cyberpsychology and Behavior, vol. 10, no. 3, pp. 482-484, 2007. 


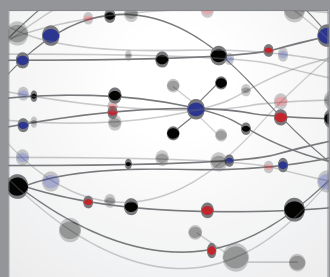

The Scientific World Journal
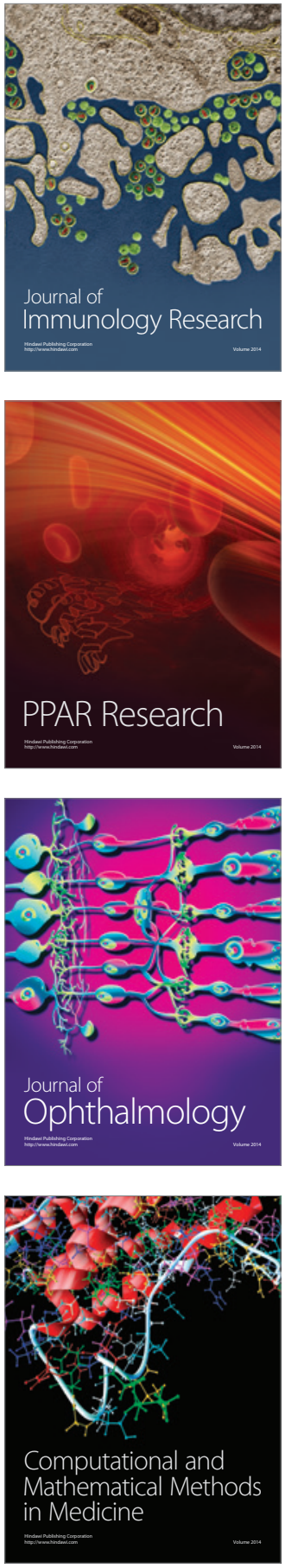

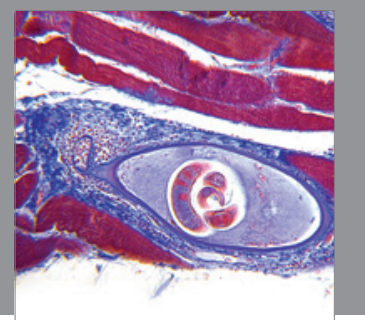

Gastroenterology

Research and Practice
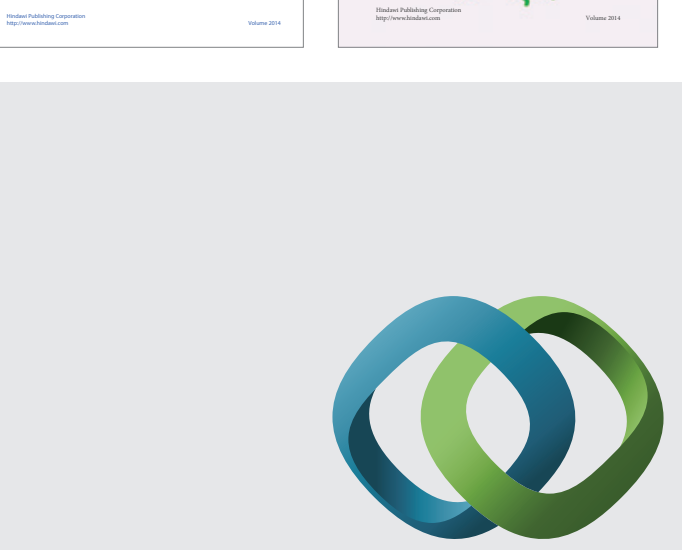

\section{Hindawi}

Submit your manuscripts at

http://www.hindawi.com
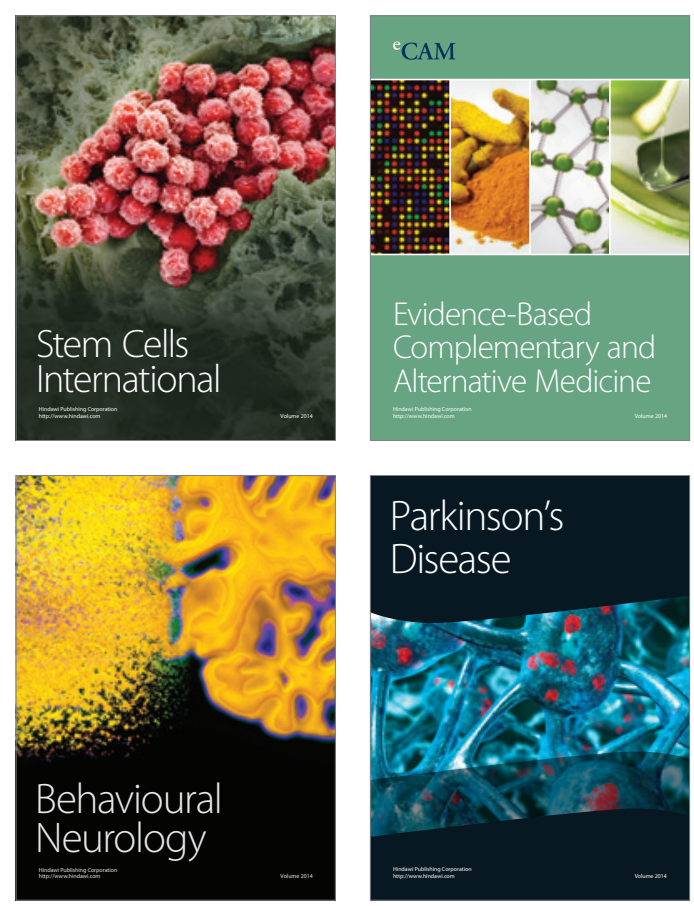

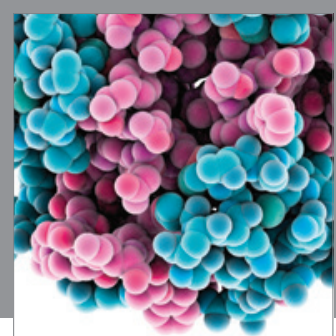

Journal of
Diabetes Research

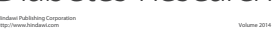

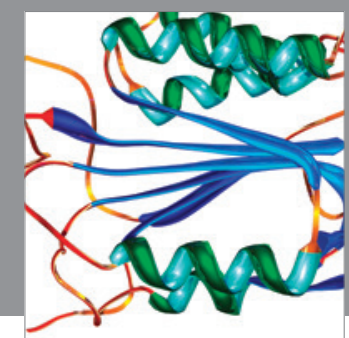

Disease Markers
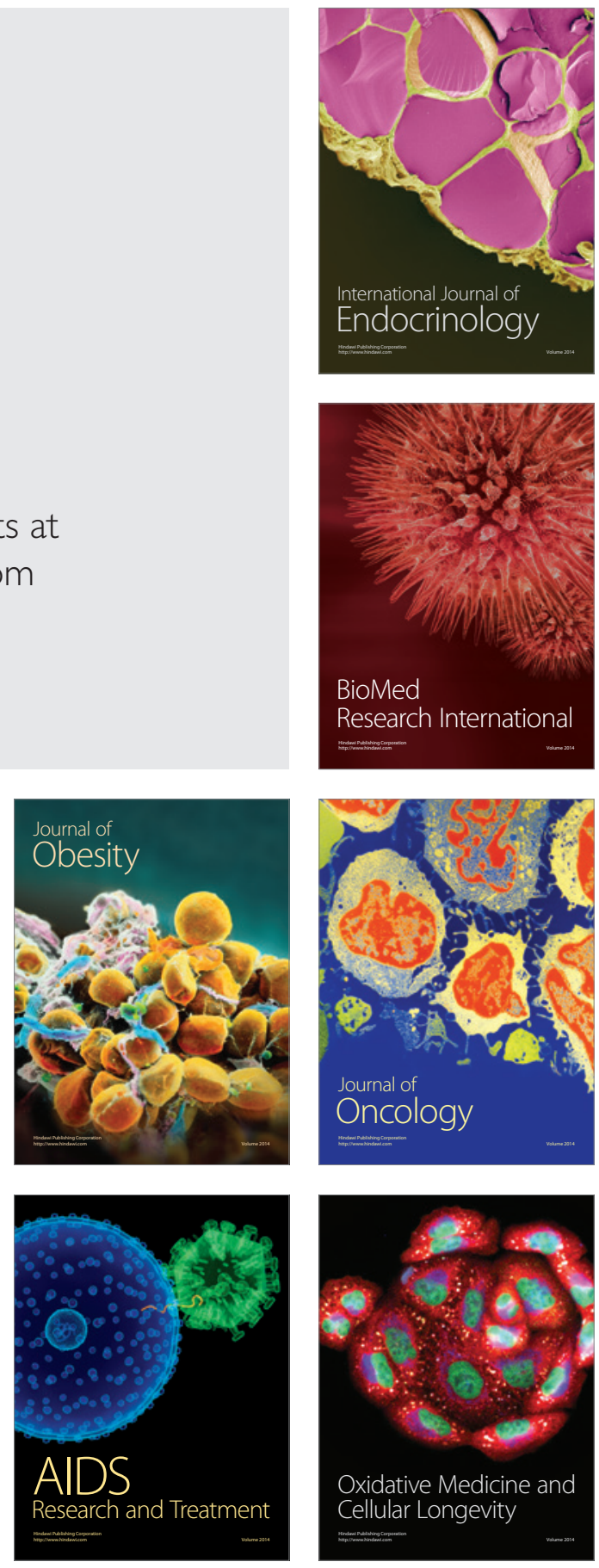